\title{
Thumb avulsion injury during pregnancy: Caution when using oxytocin
}

\author{
Jason David Archibald BSc, Richard Bendor-Samuel MD FRCSC \\ Division of Plastic Surgery, Dalhousie University, Halifax, Nova Scotia
}

\section{JD Archibald, R Bendor-Samuel. Thumb avulsion injury during pregnancy: Caution when using oxytocin. Can J Plast Surg 2001;9(4):155-158.}

A pregnant patient sustained a near complete degloving injury to her left thumb during the end of her third trimester. Surgical revascularization was successfully performed. Ten days after revascularization, the patient was induced into labour with oxytocin. Four hours after delivery, she experienced ischemic pain in the revascularized thumb, with subsequent failure and necrosis of the digit. The vasoactive properties of oxytocin are discussed, in particular, its role as a vasoconstrictor. The importance of sustaining adequate blood flow to newly revascularized tissue is stressed, as well as the need to be cautious when using vasoconstrictive agents during microvascular surgery.

Key Words: Oxytocin; Revascularization; Vasoconstrictors

\section{Oxytocine et avulsion du pouce durant la grossesse : prudence}

RÉSUMÉ : Voici le cas d'une femme enceinte qui a subi un dégantage presque complet du pouce gauche vers la fin du troisième trimestre de grossesse. On a procédé à une revascularisation chirurgicale du pouce, qui s'est avérée un succès. Dix jours plus tard, le travail a été déclenché par l'administration d'oxytocine. Quatre heures après l'accouchement, la patiente a ressenti des douleurs ischémiques au pouce revascularisé, qui se sont finalement soldées par la nécrose du doigt. Le présent article fait état d'une discussion sur les propriétés vasomotrices de l'oxytocine, notamment sur son rôle de vasoconstricteur. Il ressort également que les tissus fraîchement revascularisés ont besoin d'un apport sanguin adéquat et continu et que la prudence s'impose à l'égard des vasoconstricteurs en cours de chirurgie microvasculaire.

$\mathrm{T}$ he following case presents a pregnant patient who underwent successful thumb revascularization, which later failed following labour induction with oxytocin. The mechanism of failure is hypothesized to be due to the vasoconstrictive effects of oxytocin.

\section{CASE PRESENTATION}

A 35-year-old woman who was left hand dominant, a nonsmoker and 40 weeks pregnant was transferred to a tertiary care hospital with an avulsion injury to her left thumb. Earlier that day, she had been roping a horse. The lead had wrapped around her thumb and the horse pulled away, causing the injury. The patient was initially assessed at a rural hospital where percutaneous pinning of the digit was performed. Past medical history was unremarkable. Review of her obstetrical history revealed that the patient was gravida II, but had experienced one spontaneous abortion. At the time of presentation, she was at 40 weeks plus one day gestation, according to ultrasound. She was group B streptococcus negative.

On examination, the patient had sustained a near complete degloving injury of the left thumb at the metacarpophalangeal joint. Only the nerves and a small radial volar bridge re-

Correspondence and reprints: Dr Richard Bendor-Samuel, Division of Plastic Surgery, Queen Elizabeth II Health Sciences Centre, Halifax Infirmary, Room 4446, 1796 Summer Street, Halifax, Nova Scotia B3H 3A7. Telephone 902-473-6626, fax 902-473-8773, e-mail rbendors@IS.Dal.ca 


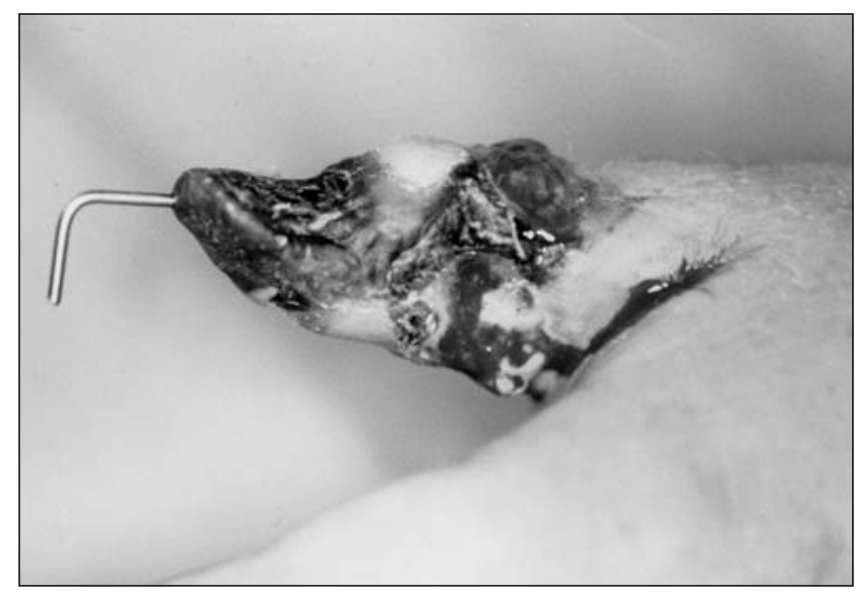

Figure 1) Failure of the patient's revascularized thumb three weeks after delivery (before revision amputation)

mained attached. The digit was completely devascularized from the injury, and the remainder of the digits on her left hand were intact and fully functional. Warm ischemia time was approximately $6 \mathrm{~h}$.

The patient was immediately taken to the operating room for revascularization of the thumb. In the lateral decubitus position, under an indwelling axillary block with bupivacaine (Marcaine; AstraZeneca, Canada), and conscious sedation with midazolam and fentanyl, the thumb was revascularized. The digital artery and vein were reanastomosed, and the extensor tendon was repaired. The flexor tendon was found to be intact, as were the digital nerves. A split-thickness skin graft was required to close the wound. Total operative time was approximately three-and-a-half hours.

In the immediate postoperative period, the patient did well and had no complications with the digit. Two days after surgery, venous congestion was noted and the thumb was treated with leeches for $12 \mathrm{~h}$. Later that evening, the patient developed pain in the digit, and the thumb looked pale and was cool to touch. There was no capillary refill, and no bleeding was elicited by needle stick. The patient was taken to the operating room immediately, and the thumb was re-explored under general anesthetic. Both vessels were patent; however, there was significant localized arterial vasospasm. The digital artery's adventitia was stripped, and the appearance of the thumb improved immediately. To lessen the risk of venous engorgement, the nail plate was removed and the nail bed was soaked with heparin. The fetal heart rate was stable throughout the procedure. Postoperatively, the patient received oral chloropromazine to decrease vasospasm and a heparin bolus of $3000 \mathrm{U}$ followed by an infusion of heparin $500 \mathrm{U} / \mathrm{h}$ for the next five days. Oral trimethoprimsulfamethoxazole was also prescribed twice daily.

Over the next five days, the thumb was treated with leeches on five occasions, and was pink and healthy on cessation of leech application. Eight days after replantation, the obstetrics department wanted to deliver the baby because the patient was one week overdue by her ultrasound dates. Two

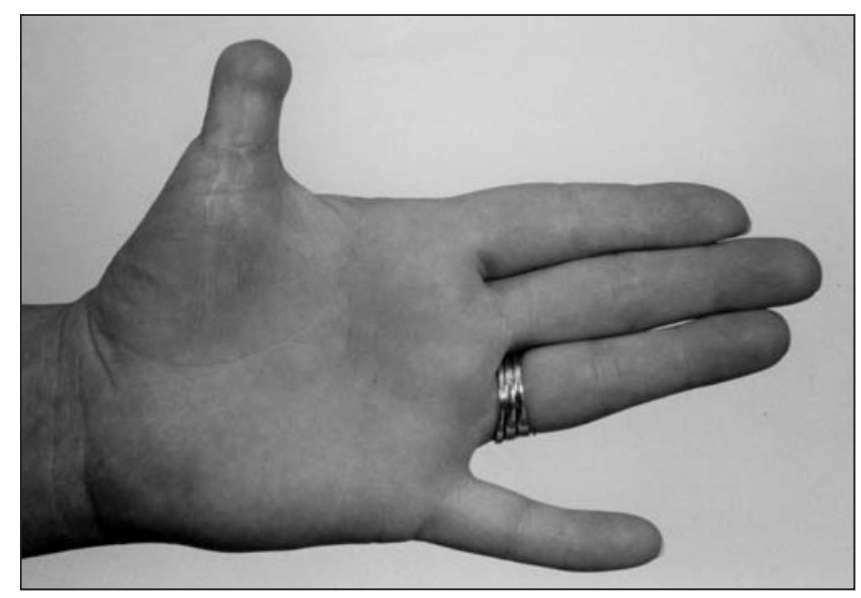

Figure 2) The patient's thumb four months after revision amputation

days later (10 days after the injury), with the thumb still looking healthy, the patient was transferred to the obstetrical hospital and labour induction commenced with an oxytocin infusion. The induction solution consisted of $10 \mathrm{U}$ of oxytocin in $500 \mathrm{~mL}$ of normal saline. The patient was started on $1 \mathrm{mU} / \mathrm{min}$, which was increased by 1 to $2 \mathrm{mU} / \mathrm{min}$ every $15 \mathrm{~min}$ (to a maximum of $40 \mathrm{mU} / \mathrm{min}$ ) until uterine activity was observed, and the oxytocin infusion was maintained throughout labour.

The process of inducing labour was successful and after a $12 \mathrm{~h}$ first stage of labour and a $2.5 \mathrm{~h}$ second stage, the patient gave birth to a healthy baby girl by vacuum-assisted vaginal delivery. There was no major blood loss during the delivery and the patient was hemodynamically stable throughout all the stages of labour. Following delivery, a second oxytocin infusion was administered that consisted of $20 \mathrm{U}$ in $500 \mathrm{~mL}$ of normal saline at 100 to $125 \mathrm{~mL} / \mathrm{h}$. Approximately $4 \mathrm{~h}$ after delivery, the patient notified a nurse of some tingling in her left thumb. Just over $12 \mathrm{~h}$ later, she complained of substantial pain in her thumb and her obstetrical doctor was notified. The thumb was blue in colour and cool to touch. Leeching was started $2 \mathrm{~h}$ later. Thirty-eight hours after delivery, there were obvious signs of failure of the digit. There were areas of patchy necrosis, absence of capillary refill and no bleeding could be elicited by needle stick. Three days later, portions of the digit were nonviable. The dead tissue was debrided, and there was some bleeding from the pulp.

The overall impression was that the tip had microthrombosed. Three weeks later (Figure 1), the patient underwent a revision amputation under local anesthetic with a splitthickness skin graft from the right thigh. The proximal phalanx was salvaged but had an atrophic appearance at followup four months later (Figure 2).

\section{DISCUSSION}

Vasoconstrictive medications administered in the early postoperative period can have a profound effect on revascularized tissue, causing ischemia and necrosis, and the eventual loss of a replanted digit (1). The first studies of oxytocin 
date back to 1906 when British scientist Sir Henry Dale (2) produced uterine contractions in cats by injecting them intravenously with posterior pituitary gland extract. Years later, Vincent du Vigneault et al $(3,4)$ identified the hormones of the posterior pituitary gland and, in 1953, proposed the molecular structure of oxytocin and created the first synthetic form of the hormone. Two years later, he received the Nobel Prize for his work. Synthetic oxytocin (Syntocinon; Novartis, Canada) is one of the most commonly used drugs in obstetrics. It is frequently used to induce and augment labour, control postpartum bleeding and prevent postpartum hemorrhage, and, less commonly, to augment postpartum milk ejection reflex.

Oxytocin is a peptide containing nine amino acids that is normally synthesized in the paraventricular and supraoptic nuclei of the hypothalamus, and stored in the posterior pituitary gland. During labour, vaginal and cervical stretching stimulate its release from the posterior pituitary gland. It then binds to receptors in the decidua, resulting in uterine contraction. This process is thought to occur by two mechanisms: directly, through an increase in intracellular calcium in the myometrial cells (5); and indirectly, through the release of decidual prostaglandins, more specifically, prostaglandin $\mathrm{F}_{2}$ (6). Oxytocin is also released in response to breast stimulation and causes contraction of mammary myoepithelial cells responsible for the milk ejection reflex (7).

Although the main effects of oxytocin involve smooth muscle contraction of the uterus and breast, it also affects the smooth muscle vasculature. A recent study demonstrated the presence and synthesis of oxytocin receptors throughout the vasculature (8). Oxytocin has a number of vasoactive properties. It is a potent constrictor of the umbilical-placental vasculature (9). It also produces constriction in numerous arteries and arterioles, including splanchnic, renal, skeletal muscle, carotid and hepatic vessels (10). At the same time, oxytocin has caused vasodilation in hepatic, splanchnic and skeletal muscle arteries in the presence of high degrees of tone (10).

Large infusion doses of oxytocin have had quite different effects on the cardiovascular system. Oxytocin is similar in structure to the other hormone of the posterior pituitary gland, vasopressin (antidiuretic hormone), and because of this, can have vasoactive and antidiuretic effects in large doses. Infusion rates of $20 \mathrm{mU} / \mathrm{min}$ or more have caused an antidiuretic effect (11). Large infusion doses have also caused vascular smooth muscle relaxation, with the potential for hypotension, tachycardia, reduced coronary perfusion and even cardiac arrest (12); however, the majority of known complications associated with oxytocin use are related to its effect on uterine activity. Once in the circulation, the molecule is not significantly protein bound, and is cleared from the blood by the maternal kidney and liver. Oxytocin has a brief plasma reduction half-life measuring between 5 and $17 \mathrm{~min}$ (13).

In general, the vasoactive properties of oxytocin are not well understood. There is limited literature available on its vascular effects, and the studies that exist are often confusing and contradictory. Oxytocin has shown vasoconstrictive and vasodilatory properties, and its contractile potencies may vary with the type of vessel involved. It has been suggested that different types of oxytocin receptors exist that subserve both contraction and relaxation, and because of this, different effects on the vasculature are seen, depending on the distribution of these receptors (14).

Whether the administration of the oxytocin drip in this patient was responsible for the loss of the revascularized thumb is uncertain. Oxytocin has vasoconstrictive properties, but when compared with other agents such as vasopressin, its posterior pituitary counterpart, its vasoconstrictive effects are quite weak (10). Also, when used in low doses, the side effects of oxytocin are thought to be quite minimal. On the other hand, microvascular anastomosis is extremely sensitive to the slightest changes in blood flow. It is possible that the oxytocin infusion initiated such a disturbance. A careful review of the case shows that the revascularized thumb was healthy until the time that the oxytocin was infused and no other factors could be identified that may have been responsible for its failure.

Finally, it is necessary to emphasize the importance of proper communication among members of the health care team. In this case, there was a $12 \mathrm{~h}$ gap between the time the patient began to experience symptoms of ischemia and when the doctor was notified. A window of opportunity may have been missed during which the digit could have been salvaged. Revascularization units, in general, should be commended on their meticulous postoperative monitoring because they tend to avoid such events. In summary, although the combination of labour induction and microvascular surgery is a rare event, oxytocin should be used with caution in these patients until more is known about its vascular effects.

\section{REFERENCES}

1. Fleming ANM. Replantation and a history of migraine headaches: Ergo(t) a warning. Plast Reconstr Surg 1999;104:484-7.

2. Dale HH. On some physiologic actions of ergot. J Physiol 1906;34:163-206.

3. du Vigneault V, Ressler C, Trippett S. The sequence of amino acids in oxytocin, with a proposal for the structure of oxytocin. J Biol Chem 1953;215:949-57.

4. du Vigneault V, Ressler C, Swan JM, et al. The synthesis of an octapeptide amide with the hormonal activity of oxytocin. J Am Chem Soc 1953;75:4879-80.

5. Tasaka K, Masumoto N, Miyake A, et al. Direct measurements of intracellular free calcium in cultured human puerperal myometrial cells stimulated by oxytocin: Effects of extracellular calcium and calcium channel blockers. Obstet Gynecol 1991;77:101-6.

6. Fuch A-R, Husslein P, Fuchs F. Oxytocin and the initiation of human parturition: II. Stimulation of prostaglandin production in human decidua by oxytocin. Am J Obstet Gynecol 1981;141:694-7.

7. Rall RW, Schleifer LS. Oxytocin, prostaglandins, ergot alkaloids, and other drugs: Tocolytic agents. In: Gilman AG, Goodman LS, Rall TW, et al, eds. The Pharmacologic Basis of Therapeutics, 7th edn. New York: Macmillan, 1985.

8. Gutowska J, Jankowski M, Mukaddam-Daher S, McCann SM. Oxytocin is a cardiovascular hormone. Braz J Med Bio Res 2000;33:625-33. 
9. Altura BM, Malaviya D, Reich CF, Orkin LR. Effects of vasoactive agents on isolated human umbilical arteries and veins. Am J Physiol 1965;208:754-62.

10. Altura BM, Altura BT. Actions of vasopressin, oxytocin, and synthetic analogs on vascular smooth muscle. Fed Proc 1984;40:80-6.

11. Abdul-Karim R, Assali NS. Renal function in human pregnancy: V. Effects of oxytocin on renal hemodynamics and water and electrolyte excretion. J Lab Clin Med 1961;57:522-32.

12. Hendriks $\mathrm{CH}$, Brenner WE. Cardiovascular effects of oxytocic drugs used postpartum. Am J Obstet Gynecol 1970;108:751-60.

13. Shyken JM, Petrie RH. The use of oxytocin. Clin Perinatol 1995;22:907-31.

14. Altura BM, Altura BT. Vascular smooth muscle and neurohypophyseal hormones. Fed Proc 1977;36:1853-60. 